\title{
Emotion and dance in dynamic light displays
}

\author{
RICHARD D. WALK and CAROLYN P. HOMAN \\ George Washington University, Washington, District of Columbia
}

\begin{abstract}
Subjects viewed and interpreted a videotape composed of point light displays from figures representing different dances and emotions. Even without cues from the face, the subjects accurately identified the dances and emotions. Discussion includes the influence of labeling, the sound of silence, sex differences in nonverbal recognition, and the alarm hypothesis about priority in recognition of emotions that threaten survival.
\end{abstract}

If points of light are placed on the joints of the human figure, with only these points visible in the dark, the lights form a meaningless pattern. When the figure moves, the neutral pattern suddenly becomes a human figure in motion. This is "event perception," research initiated by Johansson (1973; Cutting \& Proffitt, 1981).

The research described here concerns the event perception of dance and emotion. Dance is not unrelated to emotion. Levinson (cited in Copeland \& Cohen, 1983) quoted from Aristotle's description of dance in Poetics: "to imitate character, emotion and action by rhythmic movement." Our question was: Can moving light patterns depict dances? Some better than others? Emotion is usually judged from facial expression (Ekman, 1973, 1982; Izard, 1971). Although emotion may be expressed in the face, it can also be expressed in the voice and in body movement. People jump with joy or cringe with fear. How well can they recognize emotion in patterns of moving lights?

Our pilot experiment has a number of implications. These will be discussed after the experiment itself is described.

\section{METHOD}

Subjects

The subjects were 24 students at George Washington University, 11 undergraduate and 13 graduate students, 12 females and 12 males.

\section{Stimulus Materials}

Video sequence. The performer wore dark clothing, a hood over her head, gloves, and rubber-soled athletic shoes. White cotton balls were attached with Scotch tape to the shoulders, elbows, wrists, hips, knees, and ankles, 1 ball at each joint, 12 in all (see Figure 1). A drop cloth covered the wall behind the performer. The sequences were performed on a 3-m-wide area and photographed from a distance of $6 \mathrm{~m}$. All light came from a small goosenecked lamp with a $60-\mathrm{W}$ bulb placed near the TV camera $(1.25-\mathrm{cm}$ SONY AVC 3400 videocamera with accessories). By turning contrast on the TV monitor to maxi-

We thank Jacqueline Samuel for performing the mime sequences for us. Requests for reprints should be sent to: Richard D. Walk, Department of Psychology, George Washington University, Washington, DC 20052.

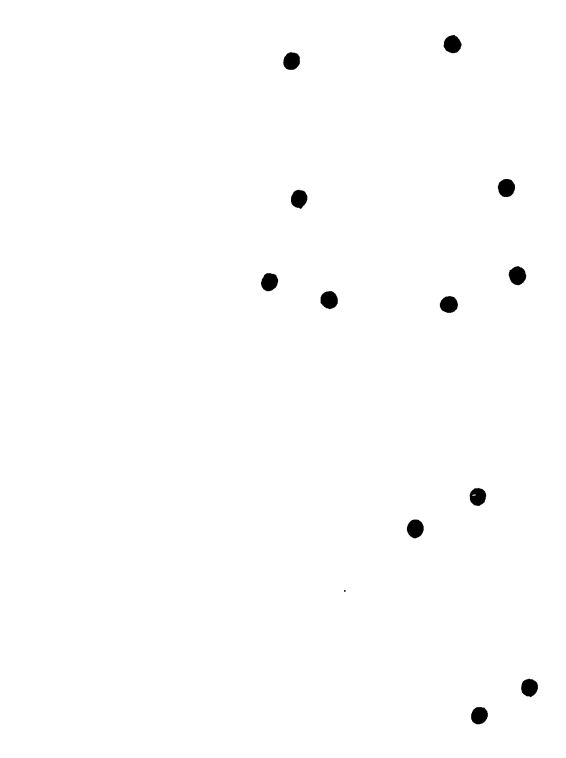

Figure 1. The human figure outlined in points of light.

mum, 12 points of light were projected onto the $27-\mathrm{cm}$-diam TV screen. The video sequence was taped for projection later.

Both performers were female. Trials 1-6 were performed by C.H., who had had extensive training in ballet and dance, and Trials $7-13$ by J.S., who had spent 2 years with a mime troupe.

The videotape contained 13 trials. The sequence for one trial was: a handwritten trial number (e.g., Trial 1) presented for $2 \mathrm{sec}$, a blank of $2 \mathrm{sec}$, the movement sequence for 10-20 sec, a blank period of $5 \mathrm{sec}$, the next trial number, etc. The 5 -sec pause between trials was a place to stop the tape so that subjects could write their responses.

The order of Trials 1-6 was: a still figure, jazz dancing, waltzing, ballet, rock and roll, and walking back and forth, each shown for $10 \mathrm{sec}$, except for walking $(15 \mathrm{sec})$. The mime sequences, Trials 7-13, were: drunkenness and sadness $(20 \mathrm{sec}$ each), happiness, fear, surprise, and anger (15 sec each), and contempt $(20 \mathrm{sec})$.

Response sheets. Response sheets had trials numbered 1-13 and space to write beside each trial number. Another sheet had the events of Trials 1-6 listed in alphabetical order, followed by the events of Trials 7-13 in alphabetical order.

\section{Procedure}

The subjects were told that they would see a series of displays identified by trial number on the monitor and that they were to answer for the appropriate trial in the space provided. 
The subjects were tested under two conditions. For the first tape presentation, the subjects were told to describe what they saw on each trial. Before the second showing, the subjects were handed the sheets with events listed in two groups. They were told to write the appropriate alternative for each trial on their response sheets, chosen from the first group on Trials 1-6 and from the second for Trials 7-13.

At the end, when the subjects had seen the tape twice, they were asked to write their estimates of the number of different figures they had seen, including the sex of the figure.

\section{RESULTS}

The first showing simply asked for written descriptions. This led to interesting responses that were helpful in assessing the technique. The second showing, when the subjects had seen the range of performances and also had the choices before them, was much more accurate.

\section{First Tape Showing}

Twenty-two of the 24 subjects identified the still person as a pattern of lights, and 2 mentioned a person (outline of a person, person standing). Examples of light patterns described were: two vertical columns, two dice, a grid of dots, a cluster of stars, lights on a runway. Although the light pattern can be identified as a person, it is also possible that some students had heard a little about our project, so the $92 \%$ nonrecognitions are more meaningful.

The second trial was "jazz," and 92\% mentioned dancing, with $17 \%$ naming it disco, modern dance, or jazz. Both waltz (42\% accurate, $83 \%$ dance) and ballet (79\% accurate, $92 \%$ dance) elicited reactions about dance, but rock and roll (46\% accurate, $67 \%$ dance) was more varied: marching, machines moving up and down, arms swinging, and swaying lights are nondance examples.

Both walking and drunkenness were easily identified on the first showing, with over $90 \%$ accuracy. Drunkenness is a classic performance for mimes.

Mimed emotional sequences were much more difficult to interpret, with the exception of anger and, much further behind, fear (see Table 1). Contempt and surprise were not identified at all on the first showing.
The miming of contempt was difficult for our subjects, as shown by some of their responses: being attacked, fear, retreating, lights back off, karate, shy, female fashion show. Surprise was quite different: singing in opera, oration, throwing kisses, accepting applause, waving to the crowd, and Luciano Pavarotti at the end of a performance, but also anger and pride.

Happiness, or a synonym for it, was spontaneously identified by $25 \%$ of our respondents, but it was also called aerobics, the cancan, rain dance, jumping, and running. Sadness had $8 \%$ correct identifications, and was also named sneaking, staggering, afraid, sick, posing like a body builder, twisting, and leaning on knees.

These spontaneous comments show that the mimed emotions elicited an interesting variety of interpretations.

\section{Second Tape Showing}

Supplying labels constrained possibilities, and Trials 1-7 were now very accurate. The only mistakes were in the confusion of jazz and rock and roll. The $71 \%$ correct for each is better than chance on the binomial test $(\mathrm{p}<.05)$.

Table 1 shows that the emotional sequences were now identified with remarkable accuracy. The two emotions unidentified initially, surprise and contempt, now had over $70 \%$ accuracy. Sadness went from $8 \%$ to $75 \%$ and happiness from $25 \%$ to $96 \%$, but anger, already correctly identified by $88 \%$, did not change, and fear increased from $42 \%$ to $71 \%$.

A comparison of this study with other studies of the facial expression of emotion is also shown in Table 1 . The agreement of mimed emotion expressed in body cues from points of light with facial emotion is remarkably accurate. The facial-expression studies had the subjects choose from a list of labels, as did this one. The only other study of emotion with points of light was that of Bassili (1978). He placed 100 points of light on the face and secured far less accurate identification than we did with 12 points placed on joints of the body, but his situation, an attempt to capture pure movement from the face, is not like the other facial studies and is hard to compare.

Table 1

Event Study Compared with Studies of Facial Expression of Emotion (Values in Percentages)

\begin{tabular}{|c|c|c|c|c|c|c|c|}
\hline & \multicolumn{2}{|c|}{ Event Study } & \multicolumn{3}{|c|}{ Ekman and Friesen's Data } & \multicolumn{2}{|c|}{ Bassili's Study } \\
\hline & $\begin{array}{c}1 \text { st } \\
\text { Time }\end{array}$ & $\begin{array}{c}\text { 2nd } \\
\text { Time }\end{array}$ & U.S. & $\begin{array}{r}\text { Literate } \\
\text { Cultures }\end{array}$ & $\begin{array}{c}\text { Fore of } \\
\text { New Guinea }\end{array}$ & $\begin{array}{l}\text { Moving } \\
\text { Full Face }\end{array}$ & $\begin{array}{c}\text { Moving } \\
\text { Spots }\end{array}$ \\
\hline Happiness & 25 & 96 & 97 & 92 & 92 & 31 & 31 \\
\hline Fear & 42 & 71 & 88 & 74 & 80 & 69 & 6 \\
\hline Surprise & 0 & 79 & 91 & 88 & 68 & 94 & 75 \\
\hline Disgust/Contempt & 0 & 71 & 82 & 84 & 81 & 88 & 57 \\
\hline Anger & 88 & 88 & 69 & 74 & 84 & 50 & 6 \\
\hline Sadness & 8 & 75 & 73 & 83 & 79 & 56 & 25 \\
\hline No. of Observers & 24 & 24 & 99 & 356 & 189 & 192 & 192 \\
\hline
\end{tabular}

Note-Literate cultures are Japan, Brazil, Chile, and Argentina. Percentages for them are a rough median of the four cultures (e.g., median of $87 \%, 97 \%, 94 \%=92 \%)$. 


\section{Miscellaneous}

The females averaged 17.6 correct responses, and the males, $15.1(\mathrm{t}=2.162, \mathrm{p}<.05)$, or $68 \%$ and $58 \%$ correct, respectively. The subjects were not accurate in a retrospective judgment of either the number or the sex of the performers.

\section{DISCUSSION}

We will discuss the following: (1) the study of emotion, (2) the sound of silence, (3) labeling or naming, (4) sex differences, (5) the alarm hypothesis, and (6) emotion and dance.

\section{The Study of Emotion}

What is emotion? How is it best studied? Most research on the external appearance of emotion is with the human face. Still photographs reveal emotion in the face, whereas body motion requires time; it is an event that requires, if not live action, motion picture film or videotape.

Reflecting the more traditional view, Tomkins (1982) wrote: "The face now appears to be still the central site of the affect responses" (p. 386). But, in the same book, Ekman (1982) wrote: "There is little excuse any longer for examining the face independently. Body movement should be considered as well as the face" (p. 396). New tools permit a broader perspective. Laban (1966), the originator of a system of notation for body movement, wrote: "We can therefore see that through bodily perspective it is possible to reveal the connection between emotion within ourselves and movement outside ourselves" (p. 91).

The present investigation supports the Laban (1966) view. Twelve points of light revealed emotion as accurately as have traditional studies of emotional expression.

\section{The Sound of Silence}

Affect has been investigated primarily with the face, but our mimed emotions are from 12 points, a body without a head as well as without a face. Yet one does not see a headless person performing a ballet. The person seems complete. Is the head constructed from past experience, through Helmholtzian "unconscious inference," or more directly perceived, an inevitable part of the perception, as Gibson (1979) might suggest? These perceptions seem direct and inevitable. Infants prefer such "biological" motions (Fox \& McDaniel, 1982), although we cannot ask them if they see a head.

The dynamic inferences from such events may be more meaningful than if the gaps are filled. Henry Moore, the sculptor, creates figures that seem in parts until one looks closely and realizes that the gaps or holes create the tension and life necessary to express the artist's vision ("Eventually I found that form and space are one and the same"-Moore, 1981,p.112). Silence can add tension to auditory beats, consonants to speech (Morse, Eilers, \& Gavin, 1982), or contours to shapes, as in "subjective contour" (Kanizsa, 1976). As with Moore's sculpture, silence can create form in all modalities.

\section{Labeling or Naming}

The studies from Ekman and Friesen (1971) and Bassili (1978) cited in Table 1 used names from which the subjects chose an appropriate response. "In every culture we studied, the observers were given the words for these emotions in their own language and were required to choose one word for each picture" (Ekman, 1973, p. 206).

Children recognize emotions from a list of emotions long before they can supply names, recognizing facial expressions for anger and happiness around age 2 years, but not labeling anger-rage until age 3-4 years (Izard, 1971).

Thus, our study fits in with other research on emotion. The use of free responses on the first trial lets us investigate whether our emotional depictions elicited appropriate names, a finding also of significance.

\section{Sex Differences}

We found that females averaged $68 \%$ correct responses and males $58 \%$. Because the difference was small and the sample was small, other factors, such as intelligence, may have been responsible. But other studies have shown that females are better than males in interpreting nonverbal behavior (Hall, 1978). Such a difference may even develop early. Caron, Caron, and Myers (1982) found 24-30-week-old female infants to be superior to males in abstracting invariant facial expressions. Although our study needs to be replicated, it does fit in with other research.

The present technique involves rotations and transformations of a light display of the human figure. Research has found that males are superior to females on spatial rotations (reviewed by authors cited in Potegal, 1982). Light displays are a different kind of spatial rotation-the observer extracts meaning from an abstract spatial rotation as distinct from mental rotation of the display itself. Are the two types of spatial rotation related? Are males superior for some types of spatial rotations and females for others?

\section{The Alarm Hypothesis}

The alarm hypothesis (Walk, 1984) refers to the alarming and alerting properties of emotions induced by threats to survival, such as anger or fear. The source of the alarm hypothesis is research with insects and birds. Wilson (1963) pointed out that the alarm pheromones for social insects are broad, whereas sexual pheromones are narrow. An alarmed social insect secretes a pheromone that alarms other social insects; sexual pheromones attract only the relevant insect species. Specific bird songs attract the female or warn away rival males, but a high-pitched continuous whistle is difficult to localize, and it warns other songbirds of the approach of a predator (Marler, 1972). Similarly with humans. An aggressive or fearful body stance may be easily communicated to our species and also to other species. But happiness is a more species-specific emotion, communicated primarily through the face and body to other humans. Thus, on the first trial, anger and fear were more spontaneously recognized than other emotions. Sackett (1966) found that orphan infant monkeys, reared without seeing monkeys or humans, avoided threatening pictures of adult monkeys. Rosenthal, Hall, DiMatteo, Rogers, and Archer (1979) found females to be especially superior in identifying negative affective cues.

\section{Emotion and Dance}

Although we have emphasized the interdependence of dance and emotion, we have somewhat skimpily discussed dance and its "beautiful transformations," as Paul Valery (cited in Copeland \& Cohen, 1983) referred to it. Arlene Croce, dance critic for The New Yorker magazine, wrote on January 30, 1984 , of program notes by choreographer Nina Wiener: "The word that leaps out at you-the word that signals the transition to the eighties-is 'emotions' ,' (p. 86). Perhaps in future research we can better investigate the interrelation of dance and emotion.

\section{REFERENCES}

BAssili, J. N. (1978). Facial motion in the perception of faces and of emotional expression. Journal of Experimental Psychology: Human Perception and Performance, 4, 373-379.

Caron, R. F., Caron, A. J., \& Myers, R. S. (1982). Abstraction of invariant face expressions in infancy. Child Development, 53, 1008-1015.

Copeland, R., \& Cohen, M. (Eds.) (1983). What is dance? Oxford: Oxford University Press. 
Croce, A. (1984, January 30). Dancing. The New Yorker, pp. 8487.

Cutring, J. E., \& Proffitr, D. R. (1981). Gait perception as an example of how we perceive events. In R. D. Walk \& H. L. Pick, Jr. (Eds.), Intersensory perception and sensory integration. New York: Plenum.

Ekman, P. (ED.) (1973). Darwin and facial expression. New York: Academic Press.

Eкмan, P. (Ed.) (1982). Emotion in the human face (2nd ed.). Cambridge: Cambridge University Press.

Ekman, P., \& Friesen, W. V. (1971). Constants across cultures in the face and emotion. Journal of Personality and Social Psychology, 17, 124-129.

Fox, R., \& McDaniel, C. (1982). The perception of biological motion by human infants. Science, 218, 486-487.

Gibson, J. J. (1979). The ecological approach to visual perception. Boston: Houghton Mifflin.

Hall, J. A. (1978). Gender effects in decoding nonverbal cues. Psychological Bulletin, 85, 845-857.

IzARD, C. E. (1971). The face of emotion. New York: AppletonCentury-Crofts.

Johansson, G. (1973). Visual perception of biological motion and a model for its analysis. Perception \& Psychophysics, 14, 201-211.

Kanizsa, G. (1976). Subjective contours. Scientific American, 234(4), 48-52.
LABAN, R. (1966). Choreutics. London: Macdonald and Evans.

Marle R, P. R. (1972). The drive to survive. In T. B. Allen (Ed.), The marvels of animal behavior. Washington: The National Geographic Society.

Moone, H. (1981). Henry Moore sculpture. New York: Rizzoli. Morse, P. A., Eilers, R. E., \& Gavin, W. J. (1982). The perception of the sound of silence in early infancy. Child Development, 53, 189-195.

Potegal, M. (Ed.) (1982). Spatial abilities. New York: Academic Press.

Rosenthal, R., Hall, J. A., DiMatteo, M. R., Rogers, P. L., \& ARCher, D. (1979). Sensitivity to nonverbal communication. The PONS test. Baltimore: Johns Hopkins University Press.

SACKe TT, G. P. (1966). Monkeys reared in isolation with pictures as visual input: Evidence for an innate releasing mechanism. Science, 154, 1468-1473.

Tomkins, S. S. (1982). Affect theory. In P. Ekman (Ed.), Emotion in the human face (2nd ed.). Cambridge: Cambridge University Press.

W Alk, R. D. (1984). Perceptual organization. In R. J. Corsini (Ed.), Encyclopedia of psychology. New York: Wiley.

Wilson, E. O. (1963). Pheromones. Scientific American, 208(5), 100-114.

(Revision received for publication July 5, 1984.) 